\title{
An agent-based co-modeling approach to simulate the evacuation of a population in the context of a realistic flooding event: a case study in Hanoi (Vietnam)
}

\author{
Kevin Chapuis ${ }^{1,3}$, Taha Amine Elwaqoudi ${ }^{1,2}$, Arthur Brugière ${ }^{1,2}$, Eric Daudé $^{7}$, \\ Alexis Drogoul ${ }^{1}$, Benoit Gaudou ${ }^{1,2,4}$, Doanh Nguyen-Ngoc ${ }^{1,6}$, Huynh Quang \\ $\mathrm{Nghi}^{1,5}$, and Jean-Daniel Zucker ${ }^{1}$ \\ 1 UMI 209 UMMISCO, Sorbonne Université, IRD, Bondy, France \\ 2 ICTLab, USTH, Vietnam Academy of Science and Technology, Hanoi, Vietnam \\ 3 UMR 228, ESPACE-DEV, IRD, Montpellier, France \\ 4 UMR 5505, IRIT, Université Toulouse 1 Capitole, Toulouse, France \\ 5 Can Tho University, Can Tho, Viet Nam \\ 6 Thuyloi University, Hanoi, Vietnam \\ 7 UMR 6266 IDEES, CNRS, Normandie University, Rouen, France \\ Contact author: kevin.chapuis@gmail.com
}

\begin{abstract}
According to recent studies, Vietnam is one of the twenty countries most affected by natural disasters in the world, and particularly by floods either on the low elevation coastal zones (risk of submersion) or along the Red River and the Mekong River (risk of flooding). In this context, dams are both means of mitigation but also threats given the possible failures and ruptures. The authorities must, therefore, prepare warning systems and evacuation plans for the downstream population to avoid loss of life. Agent-based models are now the approach of choice to support such preparedness by considering the system as a whole and integrating dynamics of different natures: hydrology, population behavior, evacuation, crisis management, etc. To design such a decision-support tool, modelers generally need to couple different formalisms, such as diffusion equations when considering the hydrodynamic part, and agent-based modeling when considering inhabitants' behaviors. This is the goal of the ESCAPE project, which uses agent-based simulations to explore evacuation strategies and contribute to the development and evaluation of evacuation plans. In this study, to improve the ESCAPE framework, we propose to combine a hydraulic dam failure model with an agent-based evacuation model using the GAMA platform. We focus on the evacuation of a Hanoi city (Vietnam) district, threatened by flooding due to the failure of the Hoa Binh dam located more than $80 \mathrm{~km}$ upstream of the city. We demonstrate how to methodologically and operationally couple a hydrodynamic water diffusion model (implemented using the HEC-RAS software) and a multi-paradigm evacuation model (using the ESCAPE framework). Our goal is to extend and enrich this population evacuation model by coupling it with flood simulation.
\end{abstract}


Keywords: Agent-based model, dam break, co-modeling, GAMA Platform, population evacuation

\section{Introduction}

The high concentrations of people and critical infrastructures in increasingly urbanized spaces make risk and disaster management highly complex [51/32] and amplify population vulnerability to hazards. Considering the poorly controlled urban development, the increasing intensity of monsoon rains, the sea level rise and the ground level subsidence in a large part of the mega cities of South East Asia located along the coasts and rivers, the population evacuation is often the only effective response to face imminent hazards. According to the world risk index [26], Vietnam is one of the twenty countries around the world with the highest vulnerability to natural hazard disasters. The country is recurrently hurt by storms, mass floods, and typhoons. As an example, in November 2017, the typhoon Damrey has killed more than 100 persons [15] in the South part of the Central Region of Vietnam. It has blown the roofs or destroyed more than 25 000 houses and forced authorities to evacuate more than 30000 persons 8 In response to the potential lost and cost due to disasters, Vietnamese authorities have launched in 2018 a large project to mitigate natural and industrial risk: 9 . The failure of the Hoa Binh dam is among the envisaged risks. Located $80 \mathrm{~km}$ upstream of Hanoi city on a tributary of the Red River, the dam is regularly forced to discharge overloaded water during the rainy season (e.g. see [62] ) and its age (it has been built in the early 90') raises concerns about potential future failures.

Among the various measures envisaged to reduce the exposure of populations to this hazard, the planning of evacuation strategies becomes a crucial concern. But evaluation of these plans coherence and of their benefits outside a crisis context is difficult. Although evacuation drills and the improvement of risk culture among the population can mitigate losses, they are generally difficult to implement [23]. The use of computer simulations to help authorities to understand the key outcomes and to anticipate the main issues related to mass population evacuation is therefore of primary interest [16. Agent-based models (ABMs) 41] are a class of computational models able to support such a preparedness by considering the system as a whole, integrating dynamics of various natures: hazards (e.g. floods), people's behaviors, crisis management... Nevertheless, to describe each of these dynamics, modelers usually have to rely on the most appropriate and efficient formalism, such as diffusion equations when considering

8 "Typhoon Damrey hits Vietnam with deadly force", The Guardian. Link: https://www.theguardian.com/world/2017/nov/04/typhoon-damrey-hits-vietnamwith-deadly-force. [Last access: August 2nd 2020].

${ }^{9}$ Vietnam Disaster Management Authority: http://phongchongthientai.mard.gov.vn/ en/Pages/priority-programs-for-disaster-risk-reduction-in-vietnam.aspx [Latest access: October 2nd 2020] 
the hydrodynamic part, or agent-based modeling when considering inhabitants' behaviors. Coupling these various models is often a challenge.

The objective of this article is thus to describe a promising co-modeling approach to couple an evacuation model of a population from a micro perspective using an ABM, and the dynamics of the disaster (an inundation) using a hydrological model. The proposed implementation relies on the GAMA platform [56], a generic agent-based modeling platform.

The article is organized as follows. Section 2 presents the case study of a catastrophic flood caused by a dam failure in northern Vietnam. Section 3 briefly describes the state of the art concerning agent-based evacuation models and the use of hydrological models in such approaches. Section 4 details the agent-based evacuation model and the hydrological flood model separately, while Section 5 focuses on the co-model implementation and presents preliminary results on both toy and real case study coupled models. Finally Section 6 summarizes the proposed approach and opens discussions about futures perspectives.

\section{Case study}

The Red River basin contains two large reservoirs (created by two dams): Thac Ba and Hoa Binh. Recently, two other dams have been built upstream of the Red River basin: Tuyen Quang and Son La Reservoirs [39]. The Hoa Binh dam, built in 1984 on the Black River, has been the largest hydropower dam in Vietnam (until 2012) and the second largest in South-East Asia with a height of $128 \mathrm{~m}$ and a length of $970 \mathrm{~m}$. Its reservoir has an area of $208 \mathrm{~km}^{2}$ with a storage capacity of $9.5 \mathrm{~km}^{3} 64$. Therefore, it has a very important strategic interest for North Vietnam and also constitutes a threat that the authorities have clearly identified ${ }^{10}$ In addition to all the people living directly downstream of the Hoa Binh dam, it is assumed that Hanoi, the capital of Vietnam, may also be at risk of flooding.

The area of study (indicated by the red rectangle in Figure 1) is thus the portion of the Red River basin located between the Hoa Binh reservoir, the dam (point 3 on Figure 1), and Hanoi city along the Black River (Da Song) and the Red River. The dam is about $60 \mathrm{~km}$ from Hanoi as the crow flies and more than $120 \mathrm{~km}$ along the river.

The main watercourses that we consider in our study are: the Red River (Hong Song) and its upstream part called Thao River (Thao Song), its confluence Clear River (Lo Song), the Black River which flows out of the Hoa Binh Reservoir, and the Duong River (Duong Song) which is a tributary of the Red River just near Hanoi.

10 Tran Quang Hoai, permanent member of the Central Steering Committee for the Prevention and Control of Natural Disasters, stated in 2018: "According to the plan, we are not allowed to let the Hoa Binh Hydropower Plant's dam break. It is necessary to actively divide the water and keep the dams safe and ensure the security of the people." 62]. 


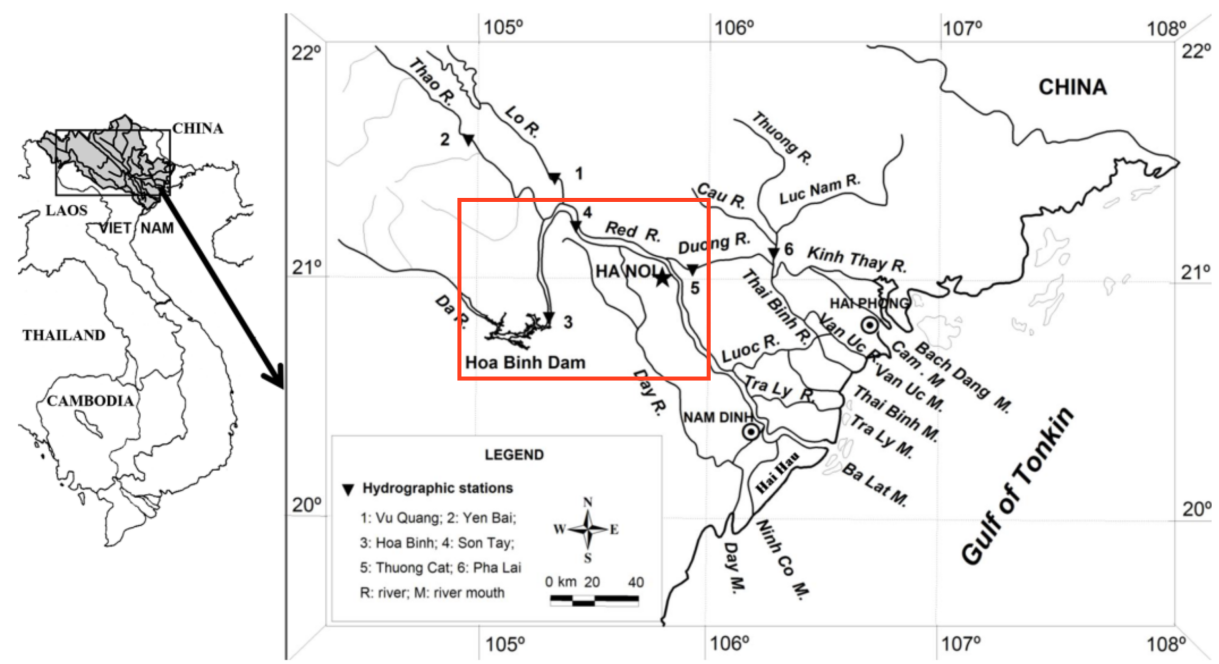

Fig. 1: Map of the Red River basin with its three main upstream tributaries and its delta area 63. The red rectangle is the simulated area.

From a topographic point of view, our case study can be divided into two parts. The Black River flows in an area surrounded by hills, but when it joins the Red River, the delta area begins and the terrain becomes flat: in particular, the entire area to Hanoi (10 meters above sea level) is mainly a flat anthropised landscape of small villages, rice fields, and dike infrastructures. The Red River delta is indeed an area that has been heavily diked for several centuries. Facing a huge amount of floods all over its history [5758, Vietnam authorities have started to build dikes in the Red River delta from 1099. P. Gourou estimates in 30] that the embankment of the whole delta has been achieved in 1865 and maintained and repaired from that time.

As far as the agent-based evacuation model is concerned, we focus on the Phuc Xa district (Figure 2). This district of Hanoi city is located between the dike and the Red River, in the north of the old quarter of Hanoi. It is quite a small urban district (around $0.92 \mathrm{~km}^{2}$ ) but highly densely populated (15767 inhabitants in the census of 2009).

Located in a risk-prone area, it has been affected by many flooding events. As an example, it was overflowed by the huge inundations that occurred in the provinces of the Red River Delta in mid-August 1971[1], killing a huge number of people ${ }^{12}$ and causing property damages evaluated to 455 million USD. More recently, the 2008 off-season heavy rain in the North and North Central Coast

${ }^{11}$ Le Hien, "A report on the big flood in 1971." People's Police Newspaper, 9, 2015. Link: http://antg.cand.com.vn/Kinh-te-Van-hoa-The-Thao/Nhin-tu-condai-hong-thuy-nam-1971-289808/[Last access: August 1st, 2020. In Vietnamese]

${ }_{12}$ Statistics indicate that 594 people have been killed, whereas other sources state the number of 100,000 people. 


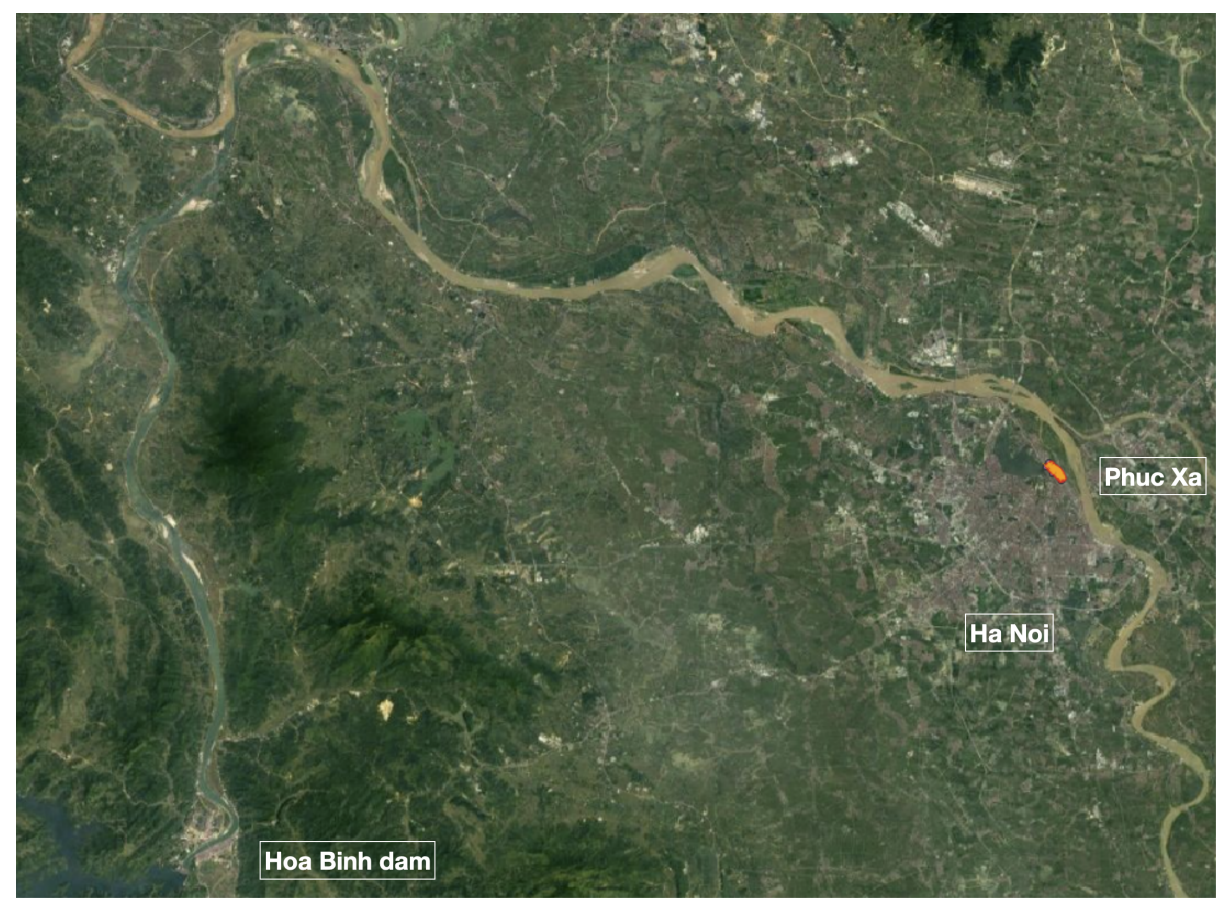

Fig. 2: Map of the Red River basin highlighting the Phuc Xa district location (Latitude : 21.04574 — Longitude : 105.848663) in the flooding area. (Source: Google Maps; access: August 1st 2020)

surpassed all expectations and caused a historic flood in Hanoi [40. These heavy rains are considered a record rainfall in the last 100 years (in 2018) and killed 17 people in the capital of Vietnam ${ }^{13}$. The damages have impacted nearly 13,000 households along the dike, flooding most houses around the Red River and tributaries. The overall amount of damage in Hanoi is estimated at least to 1260 million USD. Up to now, there is no mass evacuation plan of Hanoi identified by local authorities.

\section{State of the art}

In this section, we review the necessity and possibilities of coupling ABM and hydrological models, in particular for crisis management. In Section 3.1. we briefly introduce the main approaches and tools to model mass evacuation management using ABM. Section 3.2 discusses the various methodological and theoretical approaches to couple ABMs with dedicated domain-specific hazard models, while

13 "Vietnam floods kill 14, Hanoi streets under water", Reuters. Link: https://in. reuters.com/article/idINIndia-36242120081031 [Last access: August 1st 2020] 
in Section 3.3 we consider more closely the coupling of ABMs and hydrological models (with a focus on natural catastrophic events). Finally, Section 3.4 introduces hydrodynamic modeling of flooding due to a dam failure.

\subsection{Agent-based modeling of city evacuation and mass forced displacement management}

The agent-based modeling paradigm 41 aims at representing the behavior of a system as an emerging property of computational entities (agents) interacting with each other in a simulated environment. ABM has become an approach of choice to represent complex socio-environmental systems, especially when they require the inputs of different disciplines.

The scope of ABMs applied to the problem of evacuation, and the massive forced displacement of the urban population in particular, can be defined along one major point of departure: the general perspective considering the regime of agent mobility (e.g. horizontal or vertical) and the collective management of the evacuation (e.g. dry or during hazard, synchronous or asynchronous). When it is possible to forecast the path or extension of hazards from several hours to several days in advance, like inundations or typhoons, the focus is usually put on horizontal evacuation with the main issue being the displacement of the population to exit the risky zones [20. When the considered catastrophic event is very localized or short standing, like flash floods or tsunami, the model usually focuses on vertical evacuation [1]. In this case, the safety zone may not require massive displacement but rather the proper protective behavior 61. While the first set of models heavily rely on mobility modeling (including pedestrians, motorised traffic or multi-modal mobility) [18, social and individual responses to the alert system [54, or a global infrastructure/resource management [22], the other part of the ABM effort pays more attention to in-situ individual and collective behaviors including socio-cognitive and emotional aspects $8 / 26[60$. In recent years, several models explore the outcome of combined vertical and horizontal evacuations [44]66] even if research efforts to support this trend remain limited.

Many agent-based traffic modeling frameworks are now available to design evacuation models, the main ones include MATSim [65136, SUMO 38 25, or SimMobility [3] (see [20] for a synthetic summary). Nevertheless, when it is required to integrate individual behaviors and attitudes related to the evacuation, these platforms have limited modeling capabilities. Hence, it is often more appropriate to rely on more generic, flexible, and expressive tools such as generic agent-based modeling and simulation platforms, e.g. Netlogo [67, Repast [49] or GAMA [56. They can indeed integrate spatial data and define heterogeneous individual agents with no a priori on the architecture of agents' decisions and behaviors.

When we look at disaster management and security, the required accuracy of the hazard model will mostly depend on its suddenness and the impact of actors

on its evolution. When studying the evacuation of a population in anticipation of floods that will occur several hours later, the hazard does not necessarily need to 
be simulated: a simpler dry evacuation plan simulation model can be considered sufficient [20. The hazard would have been simulated independently and the time available to evacuate is the main information of interest for modelers and evacuation managers. Furthermore, if the hazard is expected to interfere with the evacuation (e.g. by blocking roads), pre-calculated data can be integrated into the simulation. However, when human beings' actions may alter the hazard or when the evacuation occurs during the hazard, then its dynamic needs to be coupled with the individual behavior model. For example, this is the case in a model of bushfires in the state of Victoria (Australia), where inhabitants could either evacuate in advance or stay and protect their homes 1, or during the flood of 1926 in Hanoi (Vietnam), where the inhabitants tried to protect their city from flooding by repairing or increasing the dikes [27.

In these specific cases, human behaviors models and hazard models need to be coupled in order to account for the potential interactions: human beings' actions can have an impact on the course of the hazard, while it will push people to fight or to flee the threat.

\subsection{Model coupling}

Necessity of model coupling in socio-environmental studies. Model coupling has nowadays become increasingly popular for answering research questions arising from complex systems science. Coupling can be seen as the integration or combination of different models, referred to as strong coupling. Alternatively, weak coupling can be found in a kind of data transmission between different tools and/or platforms [24.

When it comes to model socio-environmental systems, taking into account their various dimensions, interdisciplinary collaboration becomes necessary. But each research field comes with its language, vision of the systems, modeling paradigm, and even existing models. Being able to couple these models without altering them is thus a necessity to ensure the expressivity and the quality of the whole model. Besides, relying on a flexible coupling approach also improves the model scalability, providing the possibility to switch between a precise and time-consuming model and a lighter, faster, but less accurate one when upscaled or downscaled.

Several frameworks have proposed technical and operational solutions to the model coupling. Most famous ones include HLA [19], DEVS [70] or FMI [9]. As an example, DEVS proposes an event-based formalism to describe the simulation execution, considering each sub-model as a black-box only characterized by its inputs and outputs; the whole model is thus defined as a set of interconnected sub-models.

Agent-based co-modeling approaches. The question of coupling models has also been tackled in the agent-based modeling and simulation community, mainly using ad hoc approaches (such as when it comes to couple ABM and equation-based models [7/43]), while generic approaches such as HLA or DEVS are rarely applied when it comes to couple socio-environmental models [50]. 
In the following, we will rely on the co-modeling approach, introduced in 3321. Co-models have been defined as "a particular sort of agent-based models, where agents wrap one or several instances of the models to be coupled, with their life-cycle, operations, collaborations and conflict resolution mechanisms [...]". In this sense, they allow a recursive description of the system (such as in the holonic approaches ${ }^{14}$ [53, or the MADKIT platform [31]). A key point of the co-modeling approach is its ability to describe in a homogeneous way atomic agents (whose behavior is described through any given formalism) and micro-model agents, i.e. agents wrapping another model and executing it or agents calling an external simulator and reading its result data files. The main objective of the approach is to increase the expressivity of the model (by associating several modeling approaches) and reusability of its components. A key challenge of this modeling approach is the need to be able to provide a way to synchronize every agents and models in space and time.

From a general point of view, the modeling of urban evacuations relies on many dynamics such as physical models (representing the hazard), mobility models, warning systems, human behaviors, and decision-making models. Using the co-modeling approach to implement such a model could definitely take advantage of the existing literature in each of these domains and in particular from hydrodynamic modeling as far as floods are concerned.

\subsection{Coupling agent-based and hydrological models}

Coupling an agent-based evacuation model and a hydrological inundation model. Despite active researches in various domains like economics, social science, biology, military, public policy, ecology, and traffic, the literature review shows however that the agent-based modeling approach applied to stream-flow or flood forecasting problems is relatively limited [55] as it is not appropriate. Therefore this prevents a straight-forward coupling of hydrological models with agent-based models.

Conversely, the HEC-RAS software suite has recently added a module called HEC-LifeSim to simulate evacuation within the context of a realistic inundation. The main purpose is to analyse the impact of the catastrophic event on the human loss and the cost of degradation. The tool makes use of pre-simulated inundation scenarios and extends them in two main ways: first, users can define an emergency plan made of warning diffusion to alert population and protective actions initiation to define population response. The second aspect of the evacuation model is the use of an agent-based model that simulates cars or pedestrians' flight using roads, destination points, and considering damaged environment (e.g. closed road due to the inundation).

\footnotetext{
${ }^{14}$ Holonic approaches consider agents as "holons". "Holons are self-similar entities that represent whole-part constructs and can be viewed either as higher-level system components or as wholes composed of other holons as substructures." 53
} 
Hydrology in ABMs using the GAMA platform. The GAMA agentbased modeling and simulation platform [56] has been designed, in particular, to implement large-scale models of socio-environmental systems. As a consequence, many case studies have integrated a water-related model, either by coupling the GAMA model with another existing model or by implementing an ad hoc model. The choice mainly depends on the studied area extension, but also on the simulation step duration and available data. As an example, the ARCHIVES model [27] simulates the flooding of Hanoi city in 1926 and the management of this crisis by authorities. No precise data are available related to the flood state or to the topology of the river, so we built a very simple Cellular Automaton model based on the few available data (mainly a hand-made hydrograph on a single point of the river). The crisis management model and the hydraulic model are linked through the dike agents: the water presses on the dikes until they break, while authorities try to repair and reinforce them fast enough to prevent breaches. This hydrological model choice fits well with the simulation of actors' actions (which step is set to 2 hours) localized on dike as it can adapt to this time and space precision.

The MAELIA project [28] aims at assessing the social, economic, and environmental impacts of various water withdrawal policies on the Adour-Garonne (France) draining basin. Given the large area of interest and a simulation step sets to 1 day, we choose the semi-distributed watershed hydrological transport model SWAT [4. As only a subset of all the dynamics included in the SWAT model was relevant for the project, the needed equations have been implemented in the GAMA model, other dynamics being replaced by more relevant ones (e.g. the plant growth and the farmer decision-making models).

Another project 2159] explored the land use and land cover evolution in the Mekong delta due to the impact of saltwater intrusion, that reduces yields of the classical rice crops of the delta. The land-use change is controlled by yearly decisions of farmers (in terms of crops) made depending on the previous years' yields. Given the studied process, the simulation step has been set to 1 month. As a consequence, in this case, the water evolution is not computed using a hydrology model, but data are simply imported as time-series data about water height in the rivers and in the sea, to compute the intrusion of salty water.

Finally, the LittoSim [35] project built a simulation-based participative game aiming at letting decision-makers think about alternative urban planning approaches to face sea submersion and to improve the risk culture of stakeholders. To this purpose, players can manage their city with the possibility to build dikes, improve houses, or to preserve dunes... Every year a submersion is computed, given the current land use (that impacts the elevation model). To this purpose, the Littosim model is coupled with the 2D hydrodynamic model LISFLOODFL [48, which computes the submersion given the updated city infrastructures. In terms of coupling, at each step, a new Digital Elevation Model is sent from GAMA model to LISFLOOD-FL. This latter computes the submersion and returns to GAMA the casualties induced by the water. 
In this paper, we focus on floods due to dam failures; the next section presents thus a short overview of the modeling approaches regarding this kind of hazard.

\subsection{Modeling of dam breaks}

Dam break causes. Dams are under the threat of failures due to various types of events. However, the vast majority of failures have occurred on earthen embankment dams caused by extreme rainfall events 12 . Other events that can induce a dam break include natural hazards (flooding, landslide, earthquake...), failures (equipment, structure, foundation), or upstream dam failures [12].

Effects of dam breaks. Compared to other types of floods, floods caused by a dam failure are characterized by their suddenness, high flow and strong impulsive force. During a dam failure, the spread of flooding is influenced by a number of factors, such as the mode of failure, the presence and the shape of dikes along the downstream river, the elevation of the environment, the sediment transport and associated downstream hydrological and hydraulic parameters 37. Although there are many examples of dam failures in history, only a few of them are well documented and preserved. Existing records are extremely insufficient and most of them have been documented by visual observation, which implies that data related to these events are highly uncertain 42 .

Modeling dam failure and induced floods. It exists a large literature about the modeling of floods due to dam failures, using a wide variety of modeling approaches. As an example, the FLDWAV hydraulic model (a generalized flood routing model) has been used in various studies to determine the hydraulic characteristics of a flood, including its discharge, velocity, elevation, and depth at various times and distances downstream of the dam [47. Other approaches using a 2D Cellular Automaton spatial distribution model have simulated the spatio-temporal process of a dam-break flood routing [69]42].

The two main approaches used to model flooding are the hydrological approach (e.g. Muskingum method [17) and the hydrodynamic approach (e.g. solving the St. Venant equations [29]) 68. Several works have compared the 2 approaches on several case studies (e.g. dam failure-induced waves in alpine regions [52]) or in a controlled academic environment [5]. During dam failure, the saturation of the catchment area has little effect on the overall damage, as this type of flood is characterized by its suddenness and high destructiveness. Consequently, the hydrological approach is not suitable to compute the parameters in question.

In this study, we use the HEC-RAS software 11 which allows us to do 1D modeling, 2D modeling and 1D-2D coupled modeling at the same time. The latest versions of this software also have the "RAS Mapper", a tool that greatly facilitates the modeling process, the visualization of simulation results, and even more importantly, offers more data export options, which will help us later for the model coupling. 


\section{Models}

In this section, we introduce the two models (the ESCAPE evacuation ABM in Section 4.1 and the Hoa Binh dam break HEC-RAS model in Section 4.2 that will be coupled in Section 5

\subsection{ESCAPE model in a nutshell}

The ESCAPE agent-based framework [20] is dedicated to the study of urban evacuation strategies in the context of natural or technical hazard threats. It is based on four modules that describe entities and mechanisms of (i) the spatial and social environment, (ii) individual and collective decision-making processes, (iii) evacuation plans and their management, and (iv) the catastrophic event (an in-depth description has been provided in [20]). The key entity of the model is nevertheless the agents representing human beings evacuating the area, with their heterogeneity in terms of individual behavior and social characteristics. The model has been built upon a previous model of mobility in Rouen (France) [18. and extended to several case studies of urban evacuation including the Vietnamese case study of Phuc Xa (Hanoi) [13].

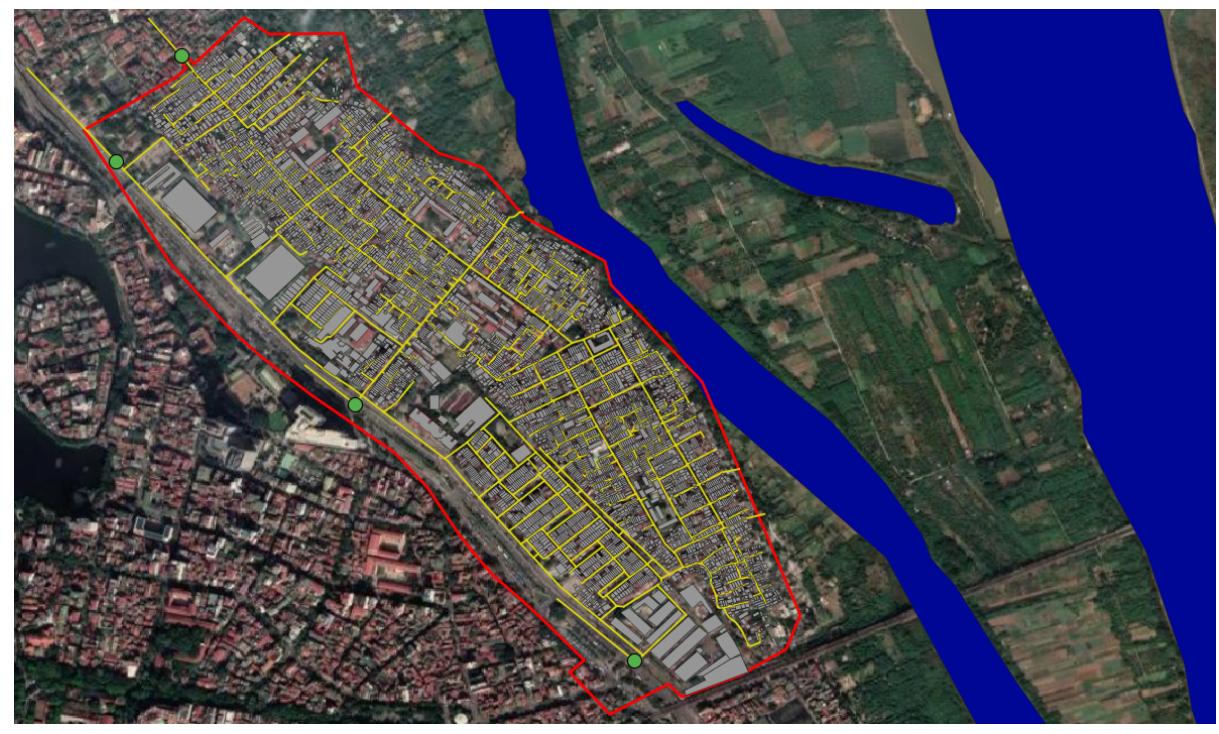

Fig. 3: Spatial data used to initialise the ESCAPE agent-based model on the Phuc Xa case study, including the ward boundary (red line), buildings (grey polygons), roads (yellow polylines), evacuation points (green circles), and the closest extends of the Red River (blue). 
Social and spatial features of the model. Figure 3 depicts the GIS data used to set up the spatial environment of the evacuation model in the quarter of Phuc Xa, Hanoi, Vietnam. The road network (yellow lines) and building footprint (grey polygons) have been gathered from OpenStreetMap (OSM) $)^{15}$. In a second step we updated the data by digitalizing misssing buildings from latest available Google satellite images. Because of data scarcity, we consider all roads to be two ways roads and practicable either for two wheels and car vehicles. The Phuc Xa quarter is surrounded by the Red River on the East and a dike (protecting the city) on the West; the evacuation points (green circles) are thus the gates in the dike accessible by roads. The height of the dike walls constitutes a major obstacle for pedestrians to cross it, they thus have to make their way towards the nearest exit gate. Considering the social environment, values of inhabitant agents' attributes have been generated using the available census dat: ${ }^{16}$ age, gender, and occupation have been assigned to reflect known aggregated demographic marginals. The location of activities (i.e. workplaces and schools) and homes have been elicited uniformly using the synthetic population generator Gen* [14].

Mobility behavior and decision during evacuation. In the ESCAPE framework, every inhabitant agent has its own set of activities during the day, i.e. its agenda. This means that when the hazard occurs, agents might already be in motion or in the course of an activity (e.g. staying at home or working). The agents' evacuation behavior can either be triggered by the event itself or an alert broadcast (e.g. siren or mobile phone messages) defined in the evacuation plan. For the Phuc Xa case study, a simplistic alert system has been designed to cope with the lack of information about the disaster as well as the absence of evacuation plan: all the agents are alerted at the same time and have to go to the nearest exit point. Most of the agents' decisions pertain to the choice of a mobility model, either using a motorbike or walking: if they are in motion, they will keep their mobility mode, whereas if they are in the middle of an activity they will choose to run directly to the exit point if the distance to their vehicle is, on average, higher than half of the distance to the exit point. Otherwise, agents go to their vehicle and follow the road to the evacuation point. The mobility speed will be altered by the congestion (correlated to the number of agents on the mobility road or pedestrian network) which thus impacts the evacuation time.

Evacuation plan. As mentioned previously, no evacuation plans are defined in advance to prepare the management of crises in Vietnam. Research questions regarding evacuation management thus move from the assessment of evacuation plans to the improvement and ease of self-evacuation, i.e. when people evacuate

$\overline{15}$ OpenStreetMap is a collaborative online GIS opendata repository: https://www. openstreetmap.org/

${ }_{10}$ Demographic data where taken from 2009 census and available at the General Statistics Office Of Vietnam https://www.gso.gov.vn/Default_en.aspx [Last access: October 11th 2020] 
by themselves. In [13, we thus investigate dry pedestrian and two wheels evacuation, with a simplistic alert system (everyone is alerted at once) to study the expected time to empty the area.

Model catastrophic event. In the ESCAPE framework, the hazard may not be implemented at all when the model focuses mainly on dry evacuation. When it is implemented in the model, it can either come as a static hazard, a set of scenarios (defining the extend areas of the hazard) or can be dynamically simulated. In all the cases, it will mainly impact the mobility of people by blocking roads and other mobility networks. In the model presented in this paper, we integrate the hazard in the evacuation simulation as results of a hydrodynamic model (see Section 4.2). It will impact the evacuation in a very simple way: when the water depth is lower than $0.5 \mathrm{~m}$, it has no impact, otherwise, it makes the evacuation impossible for the overflowed agents. Once again, we choose a simple but realistic threshold value 17 .

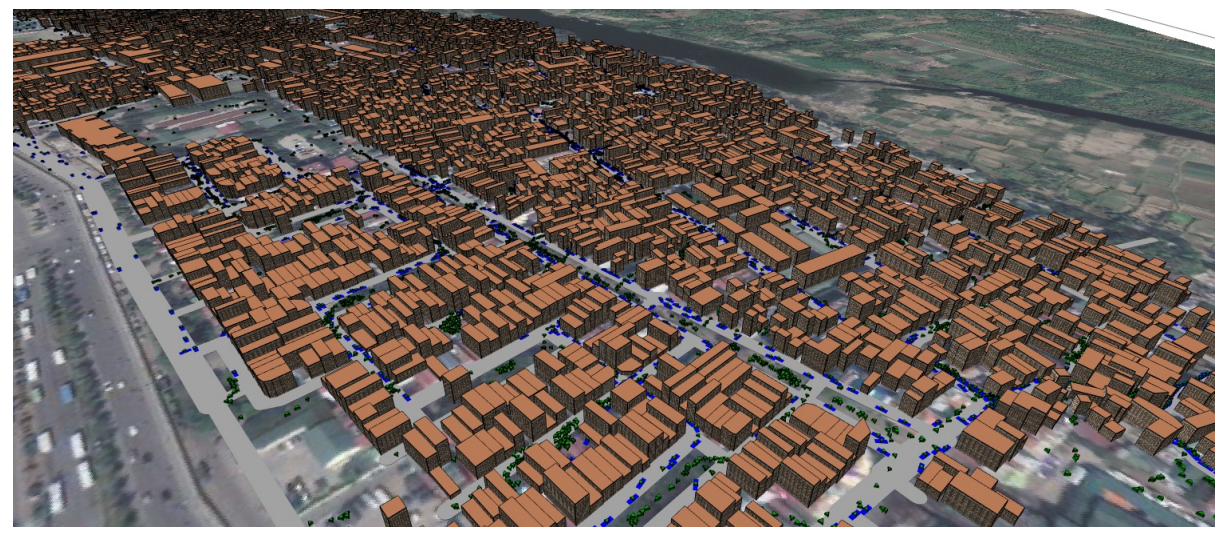

Fig. 4: ESCAPE simulation snapshot: the green triangles represent people agents and the blue rectangles the motorbikes [13].

Simulations. Figure 4 shows a snapshot of the evacuation in progress. We can observe some crowded areas for pedestrians (green triangles) and congestion on the main intersections for vehicles (blue rectangles). Because of the topology of the quarter (with only few main roads and many small pedestrian passages) and

17 A deeper investigation shows that this threshold also depends on the flow speed and human being profile, and not only on the water height. At low speed (less than 0.25 $\mathrm{m} / \mathrm{s}), 0.5 \mathrm{~m}$ is the limit for a child and 1 meter for a trained adult. At high speed $(0.75$ to $1 \mathrm{~m} / \mathrm{s})$, this threshold of $0.5 \mathrm{~m}$ is for the trained adult, the children cannot walk above 0.2 [10]. The chosen value of 0.5 has thus been chosen as an average value between the height, the speed and the human profile. 
the induced congestion, the efficiency of massive unstaged evacuations (evacuations where every agent is alerted at the same time) might be highly reduced.

\subsection{Hydrodynamic model of the dam break}

In order to model the hydrology of the studied area after the Hoa Binh dam failure, we choose to rely on the 2D modeling approach using the HEC-RAS software. To build the model, two kinds of input data are necessary: (i) topography data, including elevation and bathymetry, and (ii) water-related boundary conditions.

Input data: elevation data. The most important data to gather for hydrological modeling is the studied area elevation and topography. In this subsection we introduce the most important source, i.e. the Digital Elevation Model (DEM), and all sources to further enhance knowledge about topography related to water flows, i.e. dikes and bathymetric data among other sources.

Digital Elevation Model (DEM). For the Digital Elevation Model (DEM), we used the NASA Shuttle Radar Topography Mission (SRTM) Version 3.0 with a resolution of $30 \mathrm{~m}$ (Figure $5 \sqrt{18}$. The studied area covers the 4 provinces of Hanoi, Hoa Binh, Phu Tho and Vinh Phuc. But some preliminary simulations showed that the water front of the flood tends to go beyond the boundaries of these provinces. So we need to add 6 more neighboring provinces: Thai Nguyen, Bac Giang, Bac Ninh, Hai Duong, Hung Yen, and Ha Nam.

Dikes. Preliminary simulations have shown that, even with daily flows lower than the average flows, some water "leaks" appear in the system: the water disperses and leaves the minor river bed before the dam break. The most likely cause is that the DEM, with a resolution of $30 \mathrm{~m}$, does not take into account the dikes, which are generally $5 \mathrm{~m}$ wide. Given the importance of the dikes in the studied area, it has been necessary to integrate them more finely in the model: on the one hand to limit these "leaks", and on the other hand to have a more realistic simulation after dam failure. Using the data provided by [34, we modified the DEM to take into account the dikes.

Bathymetry. In addition to the DEM, we need bathymetric data (elevation below the water surface) along the rivers and the Hoa Binh Reservoir. However, complete bathymetric data for the entire area (Red, Black, and Clear rivers, Hoa Binh reservoir...) were not available. Therefore, we used the available data from 34 which provide bathymetry for 12 profiles across the Red River, all of them located close to the city of Hanoi. For the other sections of the Red River and other rivers, bathymetric data have been completed from various informal literature sources $\$ 19$. The main criterion used to select these data was the similarity

18 Source: https://earthexplorer.usgs.gov/

${ }^{19}$ Other sections come from the following source: https://www.geosci-model-devdiscuss.net/gmd-2019-40/ 


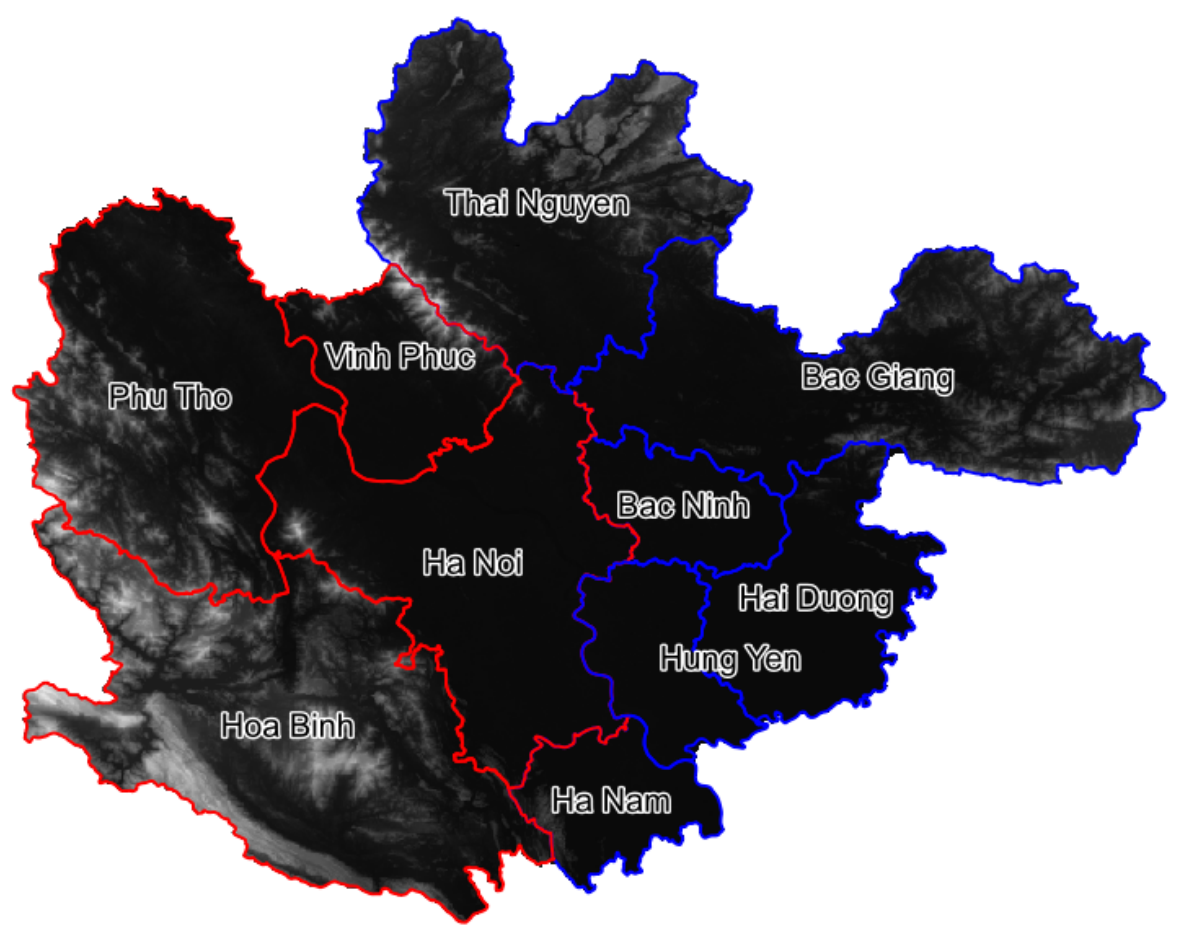

Fig. 5: Digital Elevation Model of the 10 provinces involved in the hydrodynamic model (provinces with red boundaries are the ones overlapped by the Red River, the ones with blue boundaries are the additional provinces impacted by the flooding).

of the geodetic system used. The possibility to use a small number of profiles to run the simulations is supported by related works: [45] has shown that the performance of the model is not significantly degraded when using a small number of sections (compared to the same model with a large number of cross-sectional profiles). Final dataset is shown on Figure6.

Input data: boundary conditions. In addition to the water quantity in the reservoir and the water flow coming from the dam, the simulation requires knowledge about the flows from the various tributaries and at the system outlet. For this purpose, we used flow data from a daily flow database of 5 stations over a period from 1975 to 2016 [46].

From these data, an inflow transient flow hydrograph has been created for the Black River (i.e. in the upstream of the Hoa Binh dam), Red River, and Clear River to serve as a condition for the inflow boundaries. Similarly, hydrographs have been created for outflows of the system in the Red River and Duong River. 

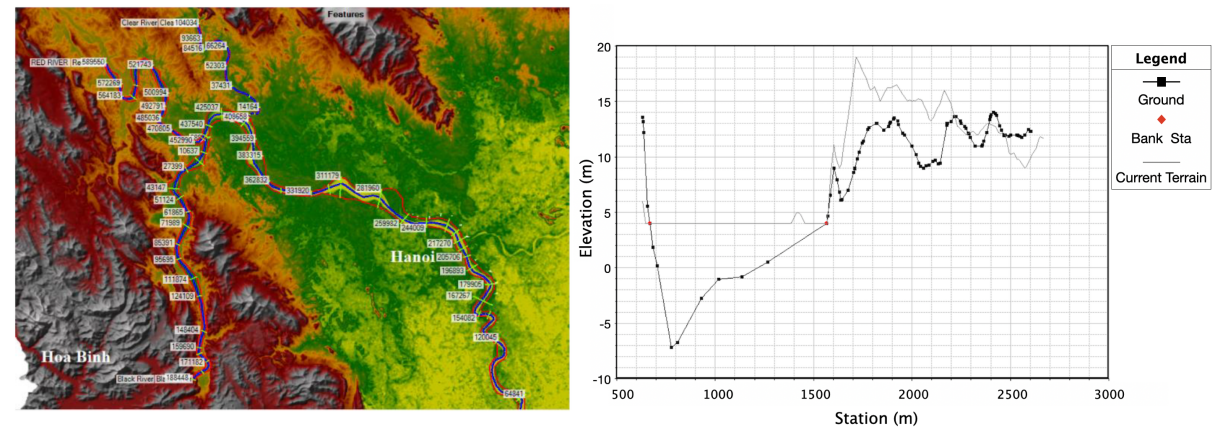

Fig. 6: Map of cross sections (left), the cross profile N 196893 after the modification of its bathymetry (right).

Description of the simulation. Before simulating the dam failure itself, it is necessary to have a hydrological state of the system close to the real state. To this purpose, we have first simulated over a period of 1 month the water flow in the system using the current boundary conditions. This allowed us to fill the rivers and the reservoir and to reach a stationary state as correct as possible.

Once the stationary state reached, the dam failure can start. Based on the characteristics of the Hoa Binh dam (presented in Section 2), the most likely mode of failure is "Pipping", i.e. an infiltration erosion [12. This is a type of failure for which, in situations where the population at risk and the study areas are sufficiently far downstream, the differences in peak flow and the shape of the hydrograph of the failure may not be significant when the flood wave reaches the downstream sections, and particularly for the Phuc Xa district in Hanoi.

This can be observed in the simulation results presented in the following section.

\subsection{Preliminary results and discussions.}

The simulations show that a first wave affects the section of the Red River near Hanoi within 24 hours. From then on, we can observe the increase in water speed and the flooding of the banks in the sections close to Hanoi. The second wave that floods a large section of the study area will not reach Hanoi before 48 more hours (72 hours since the beginning of the simulation): as depicted in figures $7 \mathrm{a}$ and $7 \mathrm{~b}$, water velocity reach two time the regular water flow in the next 3 days at the intersection between the Black and Red Rivers.

This water front propagation time, which is longer than what was expected by some experts on the field, may suggest that we have to improve the data quality and refine the model by taking into account more parameters, and in particular hydrological ones such as water evaporation and infiltration. On a global perspective, Figures $8 \mathrm{a}$ and $8 \mathrm{~b}$ show respectively the initial and the final states (i.e. at the end of the simulation, 7 days after the dam failure) of the area 


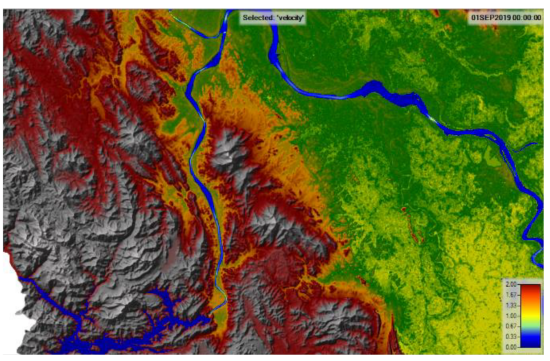

(a) Before the dam failure.

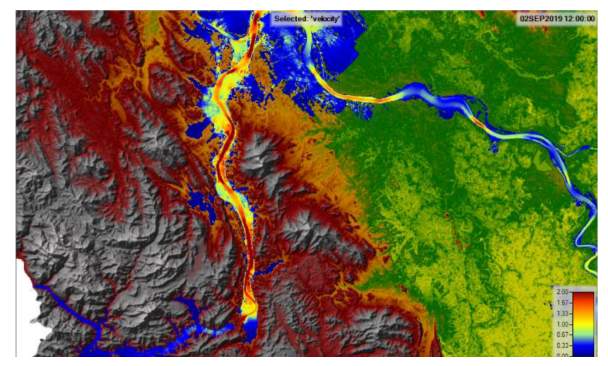

(b) 72 hours after the dam failure.

Fig. 7: Water velocity in Black and Red Rivers watercourses before and after the dam failure. Blue color stands for initial regular velocity, while yellow to red mean 1.5 times to 2 times regular velocity.

in terms of water depth. We can notice that a large portion of the studied area have been over flooded because of the dame failure.

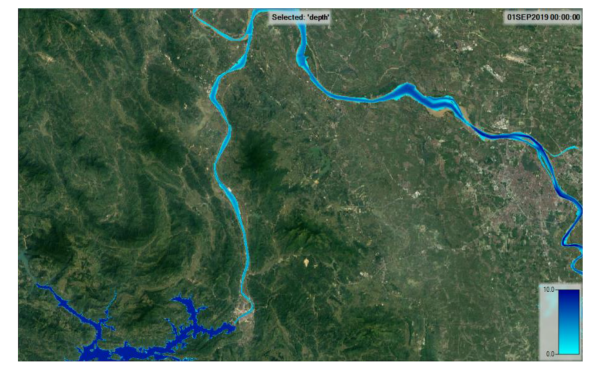

(a) Initial water depth.

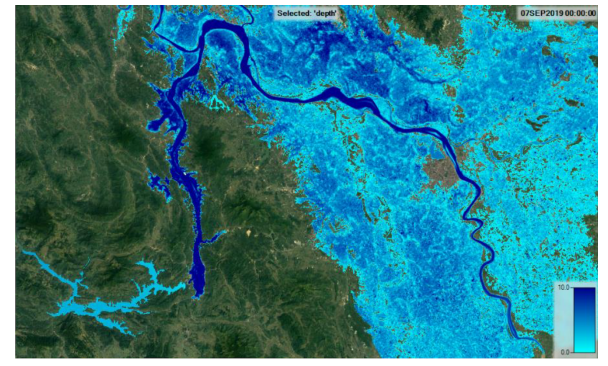

(b) Water depth 7 days after the dam break.

Fig. 8: Water depth in Black and Red Rivers watercourses before and after the dam failure. From Blue sea color stands for 10 meter depth and above to sky blue color close but superior to 0 meter depth.

It is important to notice that the city of Hanoi is not flooded after the simulated dam failure: the main reason is the quality of the DEM, which depicts building elevations rather than ground level. In order to obtain coherent flood results for the city of Hanoi, we need to improve the accuracy of data. This can be done reducing the elevation of the DEM using land registry and elevation data of buildings and roads. However, even if the model needs better data, more refinements, deeper analysis and a finer calibration procedure, the preliminary results we exposed, make it possible to use the flood model in conjunction with the agent-based model of evacuation as a proof of concept. The next section exposes the proposed coupling and its expected outcomes. 


\section{The coupled model}

\subsection{Coupling principle}

Main principles. ESCAPE main purpose is to simulate the evacuation of an urban area and not the fight against flooding (as it is the case when inhabitants try to protect their city by repairing and elevating dikes, e.g. in [27]). As a consequence, we can limit the link between the hydrodynamic and the evacuation models to a weak coupling: first, the hydraulic simulation is executed, and then the results are integrated step by step in the ABM.

To this purpose, the agent-based and the hydraulic models have to share the same environment and thus the same DEM input data. Previously executed only at the scale of the ward, the ABM has now to be upscaled to an environment that matches with the DEM. The DEM file is thus used both to define the size of the environment, the dimensions of the grid of cells that will pave the whole environment, and initialise the elevation attribute of each cell. Conversely, the flood simulation will be downscaled.

With a given frequency, a result file produced by the hydraulic simulation is read and the water depth of each grid cell is updated accordingly. It is important to notice that the hydraulic and agent-based simulation steps can be different: either water depth will not be updated at each step (if the agent-based simulation step is shorter) or all the output files will not be used if the agent-based simulation step is longer. In our case study, the ESCAPE simulation step lasts $5 \mathrm{~s}$ (because the mobility model requires a short time step to be precise enough) whereas the hydraulic simulation step lasts $10 \mathrm{~min}$. As a consequence, the water depth is updated once every 120 simulation steps in the evacuation model.

Implementation of the co-model coupling the HEC-RAS and GAMA platforms. The co-model coupling the ESCAPE and HEC-RAS models is implemented as an extension of the ESCAPE model with a grid of cells containing a water depth and an agent dedicated to wrap the HEC-RAS simulator and to interact with the other agents of the agent-based model. The coupling is made in 2 steps: (i) at initialisation, the dedicated agent calls HEC-RAS to produce results (as tif files), (ii) at each step (or every $\mathrm{N}$ steps), the wrapper agent reads one of the result files and updates the water depth of the cells of the agent-based model.

Initialisation. The GAML (GAMA Modeling Language) code shown in Listing 1.1 illustrates the first step of the coupling 20 The kind of agents hydroManager is in charge of the communication with the HEC-RAS platform. Compared to other kinds of agents, it is given additional capabilities, i.e. additional possible actions (encoded in the hecrasSkill skill). Once created, such an agent will execute at its initialisation:

${ }^{20}$ Source code is available in the Github repository of the GAMA extensions (https: //github.com/gama-platform/gama.experimental) in the ummisco.gama.extension. hecras project. 
1. Establish a connection with the HEC-RAS software. To this purpose, it first loads a new instance of the HEC-RAS engine.

2. Generate the rasmap file specifying how to execute the plan. The flooding simulation is driven by a plan that is configured through a so-called rasmap file. It specifies in particular the "terrain" and the start and end dates of the simulation.

3. Ask HEC-RAS to open an existing project. The project file contains a link to all the dataset necessary to run the simulations and to several possible plans defined by the user. A plan specifies the way a simulation is launched (which input data), if it is a steady or unsteady flow simulation in the case of a sediment simulation, and what is saved in output files every time step. The HEC-RAS project specifies the current plan to be used in step 4 .

4. Simulate the current plan specified by the project. This will create all the result files containing the water depth as .tif files. One file is created for each save time step specified in the current plan. Each file is named with the simulation time. This simulation is executed in headless mode.

5. Quit HEC-RAS software, once all the computations have been done (note that the GAMA simulation waits for the HEC-RAS simulations to be over to continue its execution).

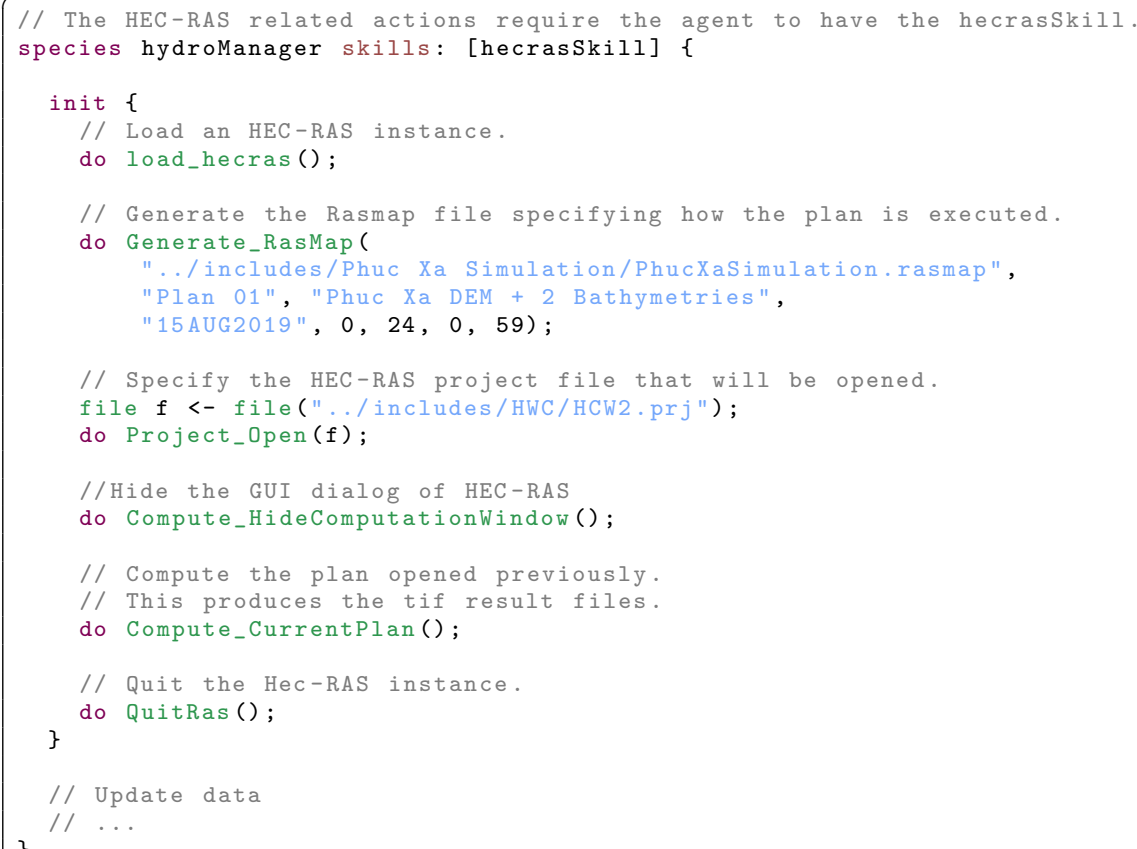

Listing 1.1: GAML code of the initialisation of the agents wrapping HEC-RAS simulations. 
Update water depth from the hydrological simulation. At every step of the ABM model, the main task for the hydroManager agent is:

1. Identify the tif file to be opened. Each result file can be identified by the simulated time it represents. As a consequence, the agent-based model has to compute a simulated time coherent with the ones of the HEC-RAS simulation. To this purpose, we rely on GAMA capabilities to manage dates: given a starting date and a duration of the simulation step, GAMA automatically computes the simulated time of the current step.

2. Read water depth of each grid cell in the opened file. The model reads the tif file and stores the results as a list of ordered float values. Given the encoding of tif files, this order is the same in all the files and it also corresponds to the order of cell agents created in the agent-based simulation.

3. Update cells. In this last step, each cell water depth value is updated. As any other agents of the simulation, cells can now impact the course of the simulation with the up-to-date flood value from the hydrological simulation.

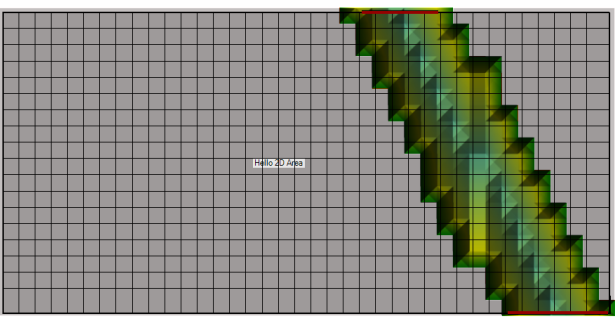

(a) Digital Elevation Model with a flat landscape and a simple river bed.

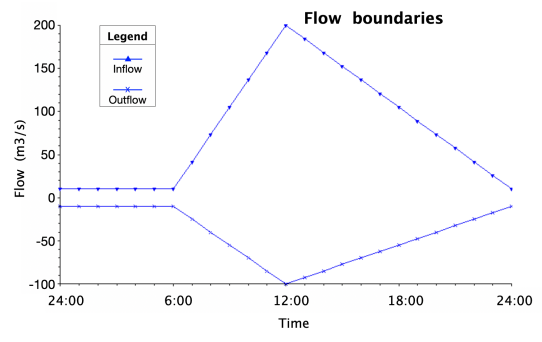

(b) Inflow and outflow hydrographs

Fig. 9: Input data of the minimal co-model.

Illustration on a minimal co-model. As an illustration of the co-model, we built a minimal co-model coupling a simple HEC-RAS model with a simple GAMA model limited to the hydrology part. The HEC-RAS model is made from data presented in Figure 9 (i) a DEM of a flat landscape with only a river bed (i.e. the greeny area), (ii) unsteady inflow and outflow hydrographs. The hydrogaphs represent the evolution of flows over a single day: from 00:00 to 06:00, flows are constant (this will fill the river and keep a stable water volume in the bed), then from 06:00 to 12:00, the inflow increases, while the outflow decreases. The river will thus soon reached its capability and the flood will occur. During the second half of the day, the inflow decreases while the outflow increases, which will reduce the flood.

Figure 10 plots the evolution of the water volume over the whole day (in the GAMA simulation), showing the constant water depth before $6 \mathrm{AM}$, and after 


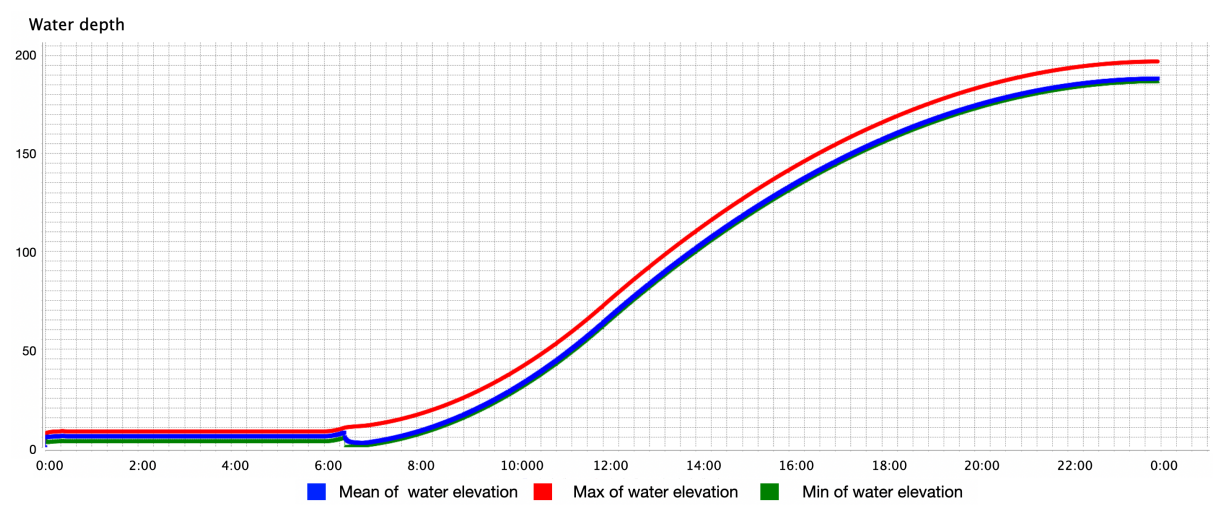

Fig. 10: Evolution of the water depth over the full day: series represent the average (blue), minimum (green) and maximum (red) water depth values in cells with water. The discontinuity at 6:20 reflects the time of flooding start (i.e. when cells outside of the river bed start to be covered by a low depth of water).

$6 \mathrm{AM}$, the water depth increase all over the day. The reduction of the inflow volume (after 12:00) only limits the increase of the water level, a maximum value seems to be reached at 0:00. The plot presents a discontinuity few minutes after 6AM: when water starts to reaches cells outside of the riverbed, they first have a very low water depth, which makes the minimum water depth decreases suddenly.

\subsection{Minimal evacuation co-model}

To go one step further and illustrate the coupling between HEC-RAS flooding simulations and a GAMA agent-based evacuation model, we implement a minimal evacuation co-model, based on the dataset used for the previous flooding co-model. It thus contains a grid of cell agents created from the DEM data file. Each cell contains an elevation (coming from the DEM file) and a water depth (updated by the wrapper agent). We add to this model (cf. Figure 11):

1. an evacuation point agent, located on the left of the environment (on a random cell, located on the column $y=0$ ).

2. a set of house agents: houses will contain initially people agents. Each house covers a full cell. Initially, the simulation creates 50 houses, located in the band of cells close to the river bed; which means they are prone to be quickly impacted by overflows.

3. people agents: one people agent is created in each house. As soon as it is alerted, it will try to escape toward the evacuation point. We force the people's move to be on the cells, and that only one agent can be located on a cell at the same time. As soon as a people agent reaches an evacuation point, it is removed from the simulation and counted as an evacuee. When a people 


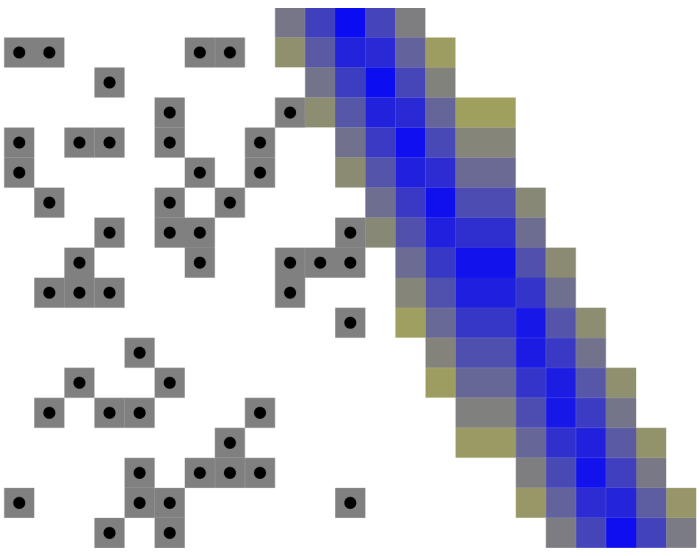

Fig. 11: Screenshot of the minimal evacuation co-model: houses (in grey) contain initially one people agent (black circle). The evacuation point is displayed with a green circle.

agent is located on a cell with a water depth higher than $2 \mathrm{~m}$, we consider that it will not be able to evacuate, it is thus removed from the simulation and counted as a casualty.

People agents will evacuate only when they are alerted by a higher-level authority. This authority (not represented explicitly in the current model) is simply characterized by an alert time parameter: when this time is reached in the simulation, all the agents are alerted and start their evacuation. To illustrate the whole workflow of coupling, we assess the evacuation process given various alert times. The explored parameter is the alert time (between 6:20 and 7:00, with a step of $5 \mathrm{~min}$ ). As for indicators, we compute the number of casualties and evacuees at the end of the simulation. Figure 12 shows the result of this exploration. We can notice that, on this toy case study, the alert can be triggered even after the increase of the inflow (and the decrease of the outflow, conditions that induce the flooding) without jeopardising the chance for everybody to be saved. Similarly, we can notice a threshold after which nobody can reach exits of the area (which might highlight the usefulness of a vertical evacuation strategy given the situation).

\subsection{Co-model coupling the ESCAPE model on the Phuc Xa area with the HEC-RAS flooding model}

The objective of this section is to demonstrate the practical capability of implementing a co-model coupling a real evacuation model (the ESCAPE model) with an HEC-RAS flooding simulation (flooding of Hanoi following the Hoa Binh dam break). A key challenge is to couple them without altering the behavior of each of them and with the minimum of modifications. This justifies the use of the co-modeling approach, wrapping the HEC-RAS simulator in an agent. 


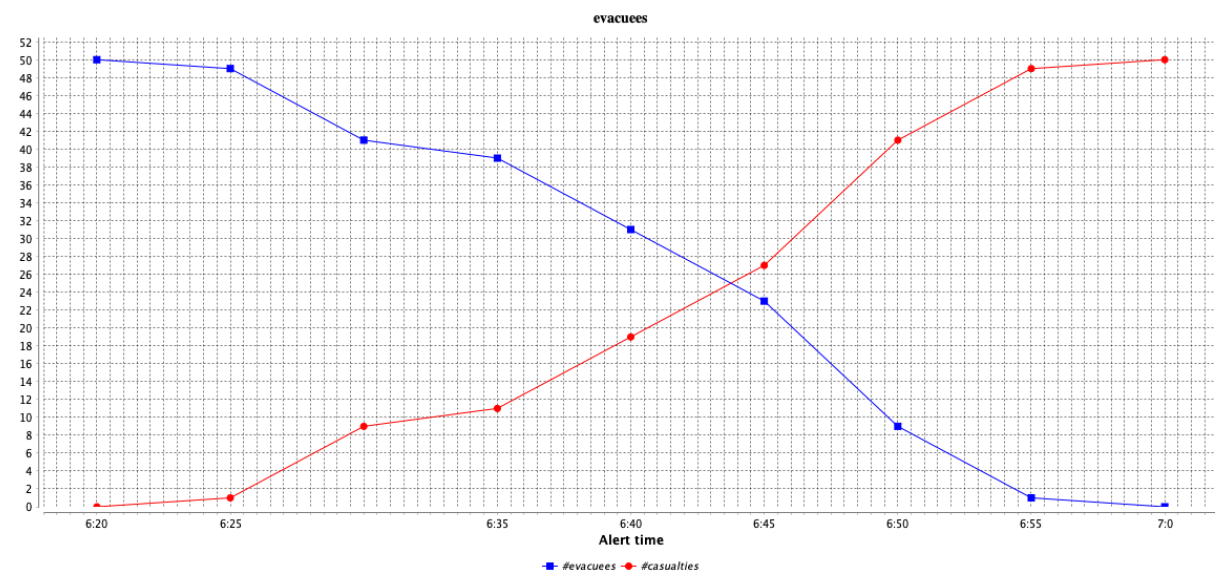

Fig. 12: Evolution of the casualties (red) and evacuees (blue) depending on the alert time.

A first adaptation is related to the dimensions of the simulation environment of both models because their spatial extensions are very different: the Phuc Xa ward is a space of less than $1 \mathrm{~km}^{2}$ whereas the hydrology is simulated on a space of around $4000 \mathrm{~km}^{2}$. We choose to run both simulations in the same environment: we thus create a new DEM file covering the Phuc Xa ward and a part of the Red River (see the central picture in Figure 13). The in- and outflow boundary conditions for this new HEC-RAS simulation come for the simulation run on the whole flooding area. The evacuation simulation is executed on a wider area. But, as the evacuation is constrained by the road and pedestrian networks, extending the overall environment dimensions will not have any impact on the evacuation simulation.

As mentioned previously, the DEM file used for the flooding simulation integrates the building height in the elevation computation, making the city not flooded as it should be. To be able to integrate the impact of the flooding on the evacuation process, the area needs to be flooded. We thus modified the elevation data in the Phuc Xa area: we apply to all the cells covering the ward the elevation of the cells without building located between the ward and the river. As depicted in Figure 13 , the overall simulated area of the Phuc Xa quarter can now eventually be submerged: the blue color intensity represents the water depth in the cell and white cells are cells without water.

The adaptation of the evacuation model has been limited to its minimum: it has simply been relocated in a bigger environment paved with a grid (defined by the DEM file used for the hydrological simulation). Each cell agent contains the water depth, updated by the wrapper agent reading the files produced by HEC-RAS.

The interaction between water level and evacuating agents will be managed by the cell agents: at each step, if a cell water depth is higher than a given 


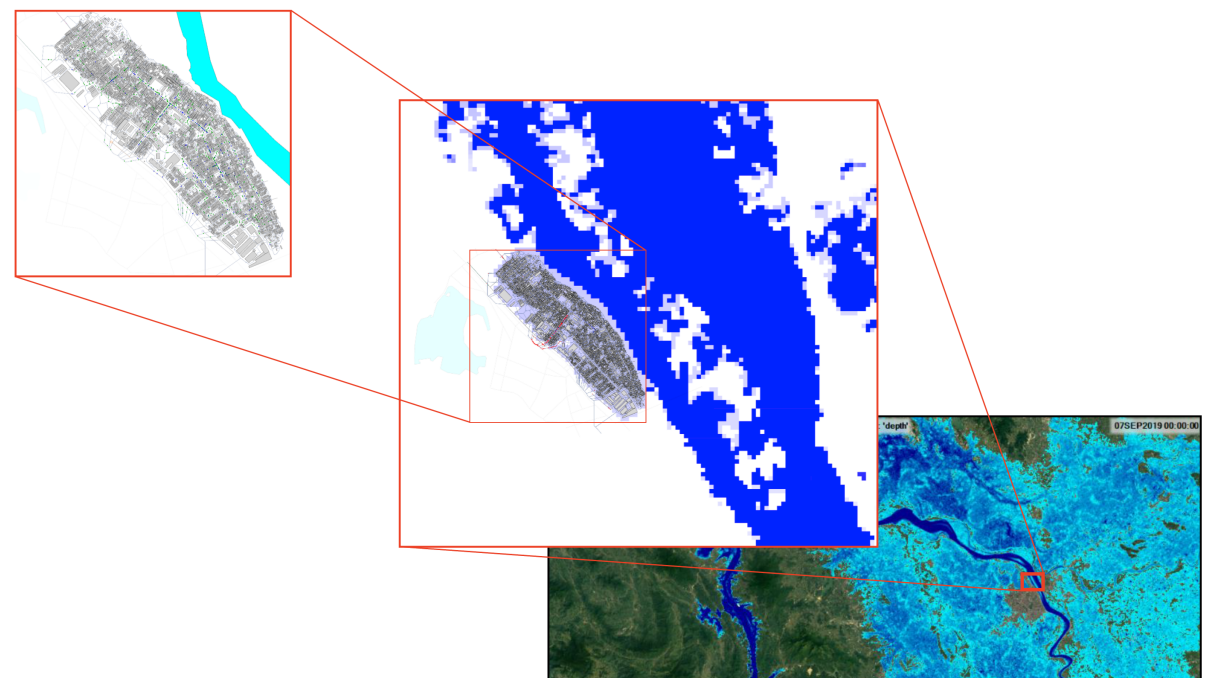

Fig. 13: ESCAPE simulation on Phuc Xa area (on the left), HEC-RAS simulation of the Hoa Binh dam break (on the right), and the coupled simulation (in the center).

threshold (chosen to $0.5 \mathrm{~m}$ in the following simulations), all the agents located on it will be removed from the simulation (and counted as non-evacuees). Finally, the alert time (the time when all the agents time are ordered to evacuate) is set as a parameter of the simulation to be explored in the following.

As a proof of concept, we explore the co-model given 2 parameters: the alert time (taken values between 6:40 and 8:00, every 10min) and the number of inhabitants (among the possible values $\{157,785,4710,7850,10990,15700\}$ ). As an indicator that can be common to all the population sizes, we chose to compute the evacuee rate: it is computed as the number of evacuee agents (at the end of the simulation) over the total number of inhabitants. An evacuation rate of 1 means that everybody was able to evacuate. Results are summarized in Figure $14 \mathrm{a}^{1}$.

First of all, we observe again that there is a range of alert time in which the model is highly sensitive: when we observe the time series for the smallest numbers of agents (175 and 785), a difference of $30 \mathrm{~min}$ in the alert time can change the output of the evacuation from a state where all the inhabitants have successfully evacuated to a state where no one was able to evacuate. After 7:40 $\mathrm{PM}$, we can also notice that nobody can evacuate. Looking at Figure 14b, we can notice that the period between 7:20PM and 7:40PM corresponds to the

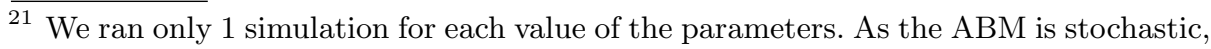
many more replications should be necessary to get accurate results. But this is out of the scope of this paper, as we focus here on the coupling from a methodological point of view. 
period where water depths reach $0.5 \mathrm{~m}$ (at 7:40PM all the cells have reached the threshold value).

Second, we can definitively observe the effect of the number of agents on the evacuation efficiency: as soon as there is a number of agents high enough (4710 in the experiment), the rate of evacuees is sharply reduced. In addition, it appears that the steepness of the curve decreases with the number of agents, which could let us imagine that the alert time (and thus the evacuation duration) needed to evacuate everyone will not be linear with the number of agents. And this can only be due to the congestion (i.e. traffic jam and crowded area) induced by a bigger number of agents evacuating at the same time.

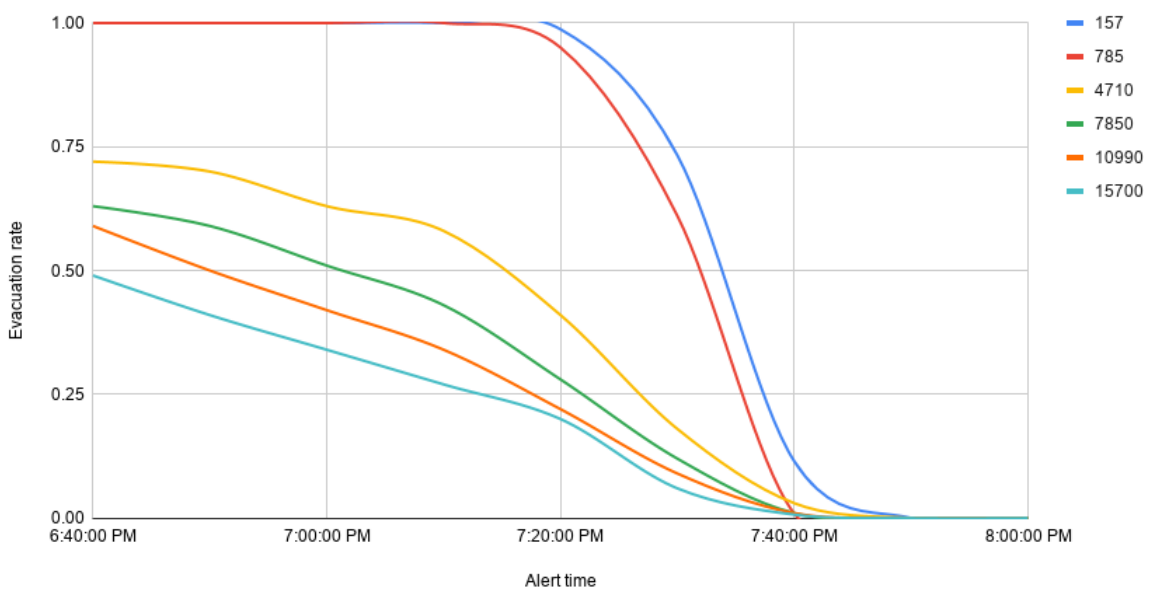

(a) Evolution of the rate of evacuees depending on the alert time and the number of inhabitants.

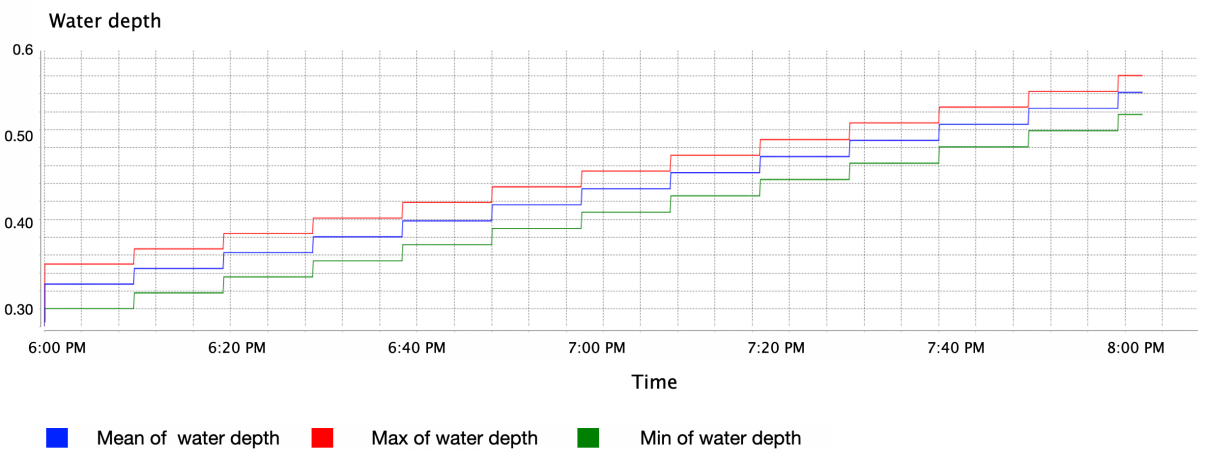

(b) Water depth evolution in the Phuc Xa ward.

Fig. 14: Input data of the minimal co-model. 


\section{Conclusion}

This paper focuses on the extension of the existing ESCAPE agent-based evacuation model, and more specifically its implementation on the Phuc Xa ward in Hanoi, threaten by flooding in case of the Hoa Binh dam failure. To this purpose we propose to combine a hydraulic dam failure model with the agent-based evacuation model using the GAMA platform. We demonstrate how to methodologically and operationally couple a hydrodynamic water diffusion model (implemented using the HEC-RAS software) and the multi-paradigm evacuation model (using the ESCAPE framework). The objective here is to integrate the evolution of the hazard, in order to be more precise in the assessment of the evacuation and in particular during the period of the flooding occurrence.

The main contribution of the paper is methodological about the coupling of two different models (different in their purpose and in their formalism), but also operational, with the extension of the GAMA platform to manage this coupling. To be more precise, contributions of this paper are (i) the design, implementation, and simulation of the inundation model on the wide area between the Hoa Binh dam and Hanoi city, (ii) the extension of the GAMA platform to interact with the HEC-RAS platform, (iii) the implementation of a minimal co-model example illustrating the coupling principles in a generic way, and (iv) the integration of the flood simulation in the agent-based evacuation model relying on the co-modeling paradigm.

This first attempt to integrate the hydrodynamic model into the ESCAPE agent-based framework makes it possible from now on to further study individual or collective responses and evacuation management strategies taking into account the evolution of the catastrophic event in a realistic way. A promising way to explore such complex interactions between the hazard and human behaviors will be to tackle thematic questions such as the ones related to synchronous versus asynchronous evacuation plans: within the context of a realistic flooding, not only congestion but fine grain water level impacts on mobility can be included as a major determinant of the evacuation strategy feasibility, drawbacks and advantages.

On a methodological aspect, even if the coupling between GAMA and HECRAS platforms is operational, it is up-to-now only in one direction: GAMA asks HEC-RAS to execute the simulation and return results that are integrated into the agent-based model during the simulation. Future works will focus on retroaction between both models in order that actions of agents can have an effect on the environment (e.g. on the elevation) which will impact back the HEC-RAS simulation.

A second interesting future work will be to propose an automatic workflow allowing the modeler to downscale the hydrodynamic simulations to a scale appropriate for the agent-based model and extract in- and outflow boundary conditions to be applied to the lower-scale simulation.

Even if it still needs to be improved, this methodological and operational coupling is really promising and it now makes it possible to tackle the question 
of improving crisis planning and evacuation plan strategies, in particular when dry evacuation is not an option.

\section{Acknowledgement}

This work is supported by the ANR ESCAPE project, grant ANR-16-CE390011-01 of the French Agence Nationale de la Recherche.

\section{References}

1. Adam, C., Gaudou, B.: Modelling human behaviours in disasters from interviews: Application to melbourne bushfires. Journal of Artificial Societies and Social Simulation 20(3), 12 (2017), http://jasss.soc.surrey.ac.uk/20/3/12.html

2. Adam, C., Taillandier, P., Dugdale, J., Gaudou, B.: Bdi vs fsm agents in social simulations for raising awareness in disasters: a case study in melbourne bushfires. International Journal of Information Systems for Crisis Response and Management (IJISCRAM) 9(1), 27-44 (2017)

3. Adnan, M., Pereira, F.C., Azevedo, C.M.L., Basak, K., Lovric, M., Raveau, S., Zhu, Y., Ferreira, J., Zegras, C., Ben-Akiva, M.: Simmobility: A multi-scale integrated agent-based simulation platform. In: 95th Annual Meeting of the Transportation Research Board Forthcoming in Transportation Research Record (2016)

4. Arnold, J.G., Srinivasan, R., Muttiah, R.S., Williams, J.R.: Large area hydrologic modeling and assessment part i: model development 1. JAWRA Journal of the American Water Resources Association 34(1), 73-89 (1998)

5. Bahrami, M., Nasab, S.B., Naseri, A.A., Albaji, M., et al.: Comparison of muskingum-cunge model and irrigation hydraulic models in estimation of furrow irrigation advance phase. Research on Crops 11(2), 541-544 (2010)

6. Bañgate, J., Dugdale, J., Beck, E., Adam, C.: A multi-agent system approach in evaluating human spatio-temporal vulnerability to seismic risk using social attachment. WIT Trans. Eng. Sci 121, 47-58 (2018)

7. Banos, A., Corson, N., Gaudou, B., Laperrière, V., Coyrehourcq, S.R.: The importance of being hybrid for spatial epidemic models: a multi-scale approach. Systems 3(4), 309-329 (2015)

8. Beck, E., Dugdale, J., Van Truong, H., Adam, C., Colbeau-Justin, L.: Crisis mobility of pedestrians: from survey to modelling, lessons from lebanon and argentina. In: International Conference on Information Systems for Crisis Response and Management in Mediterranean Countries. pp. 57-70. Springer (2014)

9. Bertsch, C., Ahle, E., Schulmeister, U.: The functional mockup interface-seen from an industrial perspective. In: Proceedings of the 10 th International Modelica Conference; March 10-12; 2014; Lund; Sweden. pp. 27-33. Linköping University Electronic Press (2014)

10. Boissier, L.: La mortalité liée aux crues torrentielles dans le Sud de la France: une approche de la vulnérabilité humaine face à l'inondation. phdthesis, Université Paul Valéry - Montpellier III (Dec 2013)

11. Bruner, G.: Hec ras, river analysis system users manual, versión 4.0. Tech. rep., US Army Corps of Engineers.(http://www. hec. usace. army. mil) (2008)

12. Brunner, G.: Using HEC-RAS for dam break studies. Tech. rep., USACE HEC Technical (2014) 
13. Chapuis, K., Taillandier, P., Gaudou, B., Drogoul, A., Daudé, E.: A multi-modal urban traffic agent-based framework to study individual response to catastrophic events. The 21st International Conference on Principles and Practice of MultiAgent Systems (PRIMA2018) p. 8 (2018)

14. Chapuis, K., Taillandier, P., Renaud, M., Drogoul, A.: Gen*: a generic toolkit to generate spatially explicit synthetic populations. International Journal of Geographical Information Science 32(6), 1194-1210 (Jun 2018), https://doi.org/10. 1080/13658816.2018.1440563

15. Committee, K.H.P.P.: 2017 vietnam post-typhoon damrey rapid damage and needs assessment. Tech. rep., WorldBank (2018), https://www.gfdrr.org/sites/default/ files/publication/vietnam-damrey-rapid-assessment-report-en.pdf

16. Cuesta, A., Abreu, O., Alvear, D.: Future Challenges in Evacuation Modelling. In: Cuesta, A., Abreu, O., Alvear, D. (eds.) Evacuation Modeling Trends, pp. 103-129. Springer International Publishing, Cham (2016), https://doi.org/10.1007/978-3319-20708-7_5

17. Cunge, J.: On the subject of a flood propagation computation method (Musklngum method). Journal of Hydraulic Research 7(2), 205-230 (1969)

18. Czura, G., Taillandier, P., Tranouez, P., Daudé, E.: MOSAIIC: City-Level AgentBased Traffic Simulation Adapted to Emergency Situations. In: Takayasu, H., Ito, N., Noda, I., Takayasu, M. (eds.) Proceedings of the International Conference on Social Modeling and Simulation, plus Econophysics Colloquium 2014, pp. 265274. Springer International Publishing, Cham (2015), http://link.springer.com/ 10.1007/978-3-319-20591-5_24

19. Dahmann, J.S., Morse, K.L.: High level architecture for simulation: An update. In: Proceedings. 2nd International Workshop on Distributed Interactive Simulation and Real-Time Applications (Cat. No. 98EX191). pp. 32-40. IEEE (1998)

20. Daudé, E., Taillandier, P., Caron, C., Gaudou, B., Saval, A., Chapuis, K., Tranouez, P., Drogoul, A., Rey-Coyrehourq, S., Zucker, J.D.: ESCAPE: Exploring by Simulation Cities Awareness on Population Evacuation. In: ISCRAM 2019. pp. 76 - 93 (2019)

21. Drogoul, A., Huynh, N.Q., Truong, Q.C.: Coupling environmental, social and economic models to understand land-use change dynamics in the mekong delta. Frontiers in environmental science 4, 19 (2016)

22. Durak, M., Durak, N., Goodman, E.D., Till, R.: Optimizing an agent-based traffic evacuation model using genetic algorithms. In: 2015 Winter Simulation Conference (WSC). pp. 288-299. IEEE (2015)

23. Fenet, J., Daudé, E.: Is population's prevention the great failure of territorial risk management: the case of the industrial risks, rouen, france. Cybergeo 932, 299-322 (2020)

24. Fianyo, Y.E.: Couplage de modèles à l'aide d'agents: le système OSIRIS. Ph.D. thesis, ANRT [diff.] (2001)

25. Flötteröd, Y.P., Erdmann, J.: Experiment study on the evacuation of bomb alert with sumo. SUMO 2016-Traffic, Mobility, and Logistics pp. 39-50 (2016)

26. Garschagen, M., Hagenlocher, M., Comes, M., Dubbert, M., Sabelfeld, R., Lee, Y.J., Grunewald, L., Lanzendörfer, M., Mucke, P., Neuschäfer, O., et al.: World risk report 2016. Tech. rep., Bündnis Entwicklung Hilft and UNU-EHS (2016)

27. Gasmi, N., Grignard, A., Drogoul, A., Gaudou, B., Taillandier, P., Tessier, O., An, V.D.: Reproducing and exploring past events using agent-based geo-historical models. In: International Workshop on Multi-Agent Systems and Agent-Based Simulation. pp. 151-163. Springer (2014) 
28. Gaudou, B., Sibertin-Blanc, C., Therond, O., Amblard, F., Auda, Y., Arcangeli, J.P., Balestrat, M., Charron-Moirez, M.H., Gondet, E., Hong, Y., et al.: The maelia multi-agent platform for integrated analysis of interactions between agricultural land-use and low-water management strategies. In: International Workshop on Multi-Agent Systems and Agent-Based Simulation. pp. 85-100. Springer (2013)

29. Gee, D.M., Brunner, G.W.: Dam break flood routing using HEC-RAS and NWSFLDWAV. In: Impacts of Global Climate Change, pp. 1-9. American Society of Civil Engineers (2005)

30. Gourou, P.: Geographie du viet nam - les paysans du delta tonkinois. Publications de L'Ecole Francaise D'extreme-Orient, 661p (1936)

31. Gutknecht, O., Ferber, J.: The $\mathrm{m}$ ad k it agent platform architecture. In: Workshop on infrastructure for scalable multi-agent systems at the international conference on autonomous agents. pp. 48-55. Springer (2000)

32. Hawe, G.I., Coates, G., Wilson, D.T., Crouch, R.S.: Agent-based simulation for large-scale emergency response: A survey of usage and implementation. ACM Computing Surveys 45(1), 1-51 (2012)

33. Huynh, Q.N.: CoModels, engineering dynamic compositions of coupled models to support the simulation of complex systems. Ph.D. thesis, Pierre and Marie Curie University (2016)

34. JICA: The study on the red river inland waterway transport system in the socialist republic of vietnam : main report ; 1. -present situation : final. Tech. rep., Japan International Cooperation Agency : The Overseas Coastal Area Development Institute of Japan (OCDI) : Japan Port Consultants, Ltd. (JPC) (2003)

35. Laatabi, A., Becu, N., Marilleau, N., Pignon-Mussaud, C., Amalric, M., Bertin, X., Anselme, B., Beck, E.: Mapping and describing geospatial data to generalize complex models: The case of littosim-gen. International Journal of Geospatial and Environmental Research 7(1), 6 (2020)

36. Lämmel, G., Klüpfel, H., Nagel, K.: The matsim network flow model for traffic simulation adapted to large-scale emergency egress and an application to the evacuation of the indonesian city of padang in case of a tsunami warning. In: Pedestrian behavior. Emerald Group Publishing Limited (2009)

37. LI, Y., LI, J.: Review of experimental study on dam-break [j]. Advances in water science 20(2), 304-310 (2009)

38. Lopez, P.A., Behrisch, M., Bieker-Walz, L., Erdmann, J., Flötteröd, Y.P., Hilbrich, R., Lücken, L., Rummel, J., Wagner, P., WieBner, E.: Microscopic traffic simulation using sumo. In: 2018 21st International Conference on Intelligent Transportation Systems (ITSC). pp. 2575-2582. IEEE (2018)

39. Lu, X.X., Oeurng, C., Le, T.P.Q., Thuy, D.T.: Sediment budget as affected by construction of a sequence of dams in the lower Red River, Viet Nam. Geomorphology 248, 125-133 (2015)

40. Luo, P., Mu, D., Xue, H., Ngo-Duc, T., Dang-Dinh, K., Takara, K., Nover, D., Schladow, G.: Flood inundation assessment for the hanoi central area, vietnam under historical and extreme rainfall conditions. Scientific reports 8(1), 1-11 (2018)

41. Macal, C., North, M.: Tutorial on agent-based modelling and simulation. J. Simulation 4, 151-162 (2010)

42. Mao, J., Wang, S., Ni, J., Xi, C., Wang, J.: Management system for dam-break hazard mapping in a complex basin environment. ISPRS International Journal of Geo-Information 6(6), 162 (2017)

43. Marilleau, N., Lang, C., Giraudoux, P.: Coupling agent-based with equation-based models to study spatially explicit megapopulation dynamics. Ecological modelling $384,34-42(2018)$ 
44. Mas, E., Adriano, B., Koshimura, S., Laboratory of Remote Sensing and Geoinformatics for Disaster Management, International Research Institute of Disaster Science, Tohoku University, Aoba 6-6-3, Sendai 980-8579, Japan: An Integrated Simulation of Tsunami Hazard and Human Evacuation in La Punta, Peru. Journal of Disaster Research 8(2), 285-295 (Mar 2013), https://www.fujipress.jp/jdr/ dr/dsstr000800020285

45. Md Ali, A., Di Baldassarre, G., Solomatine, D.P.: Testing different cross-section spacing in 1d hydraulic modelling: a case study on johor river, malaysia. Hydrological Sciences Journal 60(2), 351-360 (2015)

46. Meteorological, V., Administration, H.: Data base of water discharge of 5 stations from 1975 to 2016. Tech. rep., LMI LOTUS - USTH (2016)

47. Michaud, J., Johnson, C., Iokepa, J., Marohnic, J.: Methods for estimating the impact of hypothetical dam break floods. In: Chemistry for the Protection of the Environment 4, pp. 195-199. Springer (2005)

48. Neal, J., Schumann, G., Fewtrell, T., Budimir, M., Bates, P., Mason, D.: Evaluating a new lisflood-fp formulation with data from the summer 2007 floods in tewkesbury, uk. Journal of Flood Risk Management 4(2), 88-95 (2011)

49. North, M.J., Collier, N.T., Ozik, J., Tatara, E.R., Macal, C.M., Bragen, M., Sydelko, P.: Complex adaptive systems modeling with repast simphony. Complex adaptive systems modeling 1(1), 3 (2013)

50. Parrott, L.: Hybrid modelling of complex ecological systems for decision support: Recent successes and future perspectives. Ecological informatics 6(1), 44-49 (2011)

51. Perrow, C.: The Next Catastrophe: Reducing Our Vulnerabilities to Natural, Industrial, and Terrorist Disasters. Princeton University Press (2007)

52. Pilotti, M., Maranzoni, A., Milanesi, L., Tomirotti, M., Valerio, G.: Dam-break modeling in alpine valleys. Journal of Mountain Science 11(6), 1429-1441 (2014)

53. Rodriguez, S., Hilaire, V., Gaud, N., Galland, S., Koukam, A.: Holonic multi-agent systems. In: Di Marzo Serugendo, G., Gleizes, M.P., Karageorgos, A. (eds.) Selforganising Software: From Natural to Artificial Adaptation, pp. 251-279. Springer Berlin Heidelberg, Berlin, Heidelberg (2011)

54. Ruin, I., Lutoff, C., Boudevillain, B., Creutin, J.D., Anquetin, S., Rojo, M.B., Boissier, L., Bonnifait, L., Borga, M., Colbeau-Justin, L., Creton-Cazanave, L., Delrieu, G., Douvinet, J., Gaume, E., Gruntfest, E., Naulin, J.P., Payrastre, O., Vannier, O.: Social and Hydrological Responses to Extreme Precipitations: An Interdisciplinary Strategy for Postflood Investigation. Weather, Climate, and Society 6(1), 135-153 (Jan 2014)

55. Simmonds, J., Gómez, J.A., Ledezma, A.: The role of agent-based modeling and multi-agent systems in flood-based hydrological problems: a brief review. Journal of Water and Climate Change p. jwc2019108 (Oct 2019)

56. Taillandier, P., Gaudou, B., Grignard, A., Huynh, Q.N., Marilleau, N., Caillou, P., Philippon, D., Drogoul, A.: Building, composing and experimenting complex spatial models with the GAMA platform. GeoInformatica 23(2), 299-322 (2019)

57. Tessier, O.: Outline of the process of red river hydraulics development during the nguyen dynasty (nineteenth century). In: Environmental change and agricultural sustainability in the Mekong Delta, pp. 45-68. Springer (2011)

58. Tessier, O.: Hydrological development of the red river delta: a historical perspective of the role of the imperial then colonial state (From the XIIth century to the first half of the XXth century). Water and its Many Issues. Methods and Cross-cutting Analysis, Regional Social Sciences Summer University pp. 130-154 (2012) 
59. Truong, Q.C., Taillandier, P., Gaudou, B., Vo, M.Q., Nguyen, T.H., Drogoul, A.: Exploring agent architectures for farmer behavior in land-use change. a case study in coastal area of the vietnamese mekong delta. In: International workshop on multi-agent systems and agent-based simulation. pp. 146-158. Springer (2015)

60. Valette, M., Gaudou, B., Longin, D., Taillandier, P.: Modeling a real-case situation of egress using bdi agents with emotions and social skills. In: International Conference on Principles and Practice of Multi-Agent Systems. pp. 3-18. Springer (2018)

61. Velotti, L., Trainor, J.E., Engel, K., Torres, M., Myamoto, T.: Beyond vertical evacuation: Research considerations for a comprehensive" vertical protection strategy". International Journal of Mass Emergencies \& Disasters 31(1) (2013)

62. VietnamNews: (2018), https://vietnamnews.vn/society/462709/hoa-binh-son-lahydroelectric-plants-ensure-safety.html, (accessed on June, the 29th 2020)

63. Vinh, V., Ouillon, S., Thanh, T., Chu, L.: Impact of the Hoa Binh dam (Vietnam) on water and sediment budgets in the Red River basin and delta. Hydrology and Earth System Sciences 18(10), 3987 (2014)

64. $\mathrm{Vu}, \mathrm{V}$.: The Hoa Binh reservoir and the general gestation of its basin area. General Centre for Meteorology and Hydrology of Vietnam 250 (2002)

65. W Axhausen, K., Horni, A., Nagel, K.: The multi-agent transport simulation MATSim. Ubiquity Press (2016)

66. Wang, H., Mostafizi, A., Cramer, L.A., Cox, D., Park, H.: An agent-based model of a multimodal near-field tsunami evacuation: Decision-making and life safety. Transportation Research Part C: Emerging Technologies 64, 86-100 (Mar 2016), http://www.sciencedirect.com/science/article/pii/S0968090X15004106

67. Wilensky, U.: Netlogo itself: Netlogo. Tech. rep., Center for Connected Learning and Computer-Based Modeling, Northwestern University, Evanston, http://ccl. northwestern. edu/netlogo (1999)

68. Xiong, Y.F.: A dam break analysis using HEC-RAS. Journal of Water Resource and Protection 3(6), 370 (2011)

69. Yin, L., Zhu, J., Zhang, X., Li, Y., Wang, J., Zhang, H., Yang, X.: Visual analysis and simulation of dam-break flood spatiotemporal process in a network environment. Environmental Earth Sciences 74(10), 7133-7146 (2015)

70. Zeigler, B.P., Moon, Y., Kim, D., Ball, G.: The devs environment for highperformance modeling and simulation. IEEE Computational Science and Engineering 4(3), 61-71 (1997) 